\title{
PROPRIEDADES FÍSICO-MECÂNICAS DE BLOCOS SÍLICO CALCÁRIOS INCORPORANDO RESÍDUO CALCÁRIO
}

\author{
A. M. D. Sousa, D. S. S. Moura, C. A. Paskocimas² e M. L. Varela \\ ${ }^{1}$ Instituto Federal do Rio Grande do Norte - Campus Mossoró e ${ }^{2}$ Depto de Eng. de Materiais - UFRN \\ alexmicael@hotmail.com -marcio.varela@ifrn.edu.br -darcia.moura@ifrn.edu.br-paskocimas@ufrnet.br
}

Artigo submetido em maio/2011 e aceito em junho/2011

\section{RESUMO}

Um dos fundamentos da realização desta pesquisa refere-se à possibilidade de minimizar os impactos ambientais decorrentes da exploração da rocha calcária. Nesta vertente, esta pesquisa apresenta um estudo de caráter experimental voltado à incorporação de resíduo calcário em formulações de blocos sílico-calcários para alvenaria estrutural, avaliando a viabilidade técnica de produção destes através da determinação de suas propriedades físicomecânicas, representadas nesta pesquisa pela retração linear de cura, absorção de água, porosidade aparente, massa específica aparente e módulo de ruptura à flexão em três pontos. Ao término do estudo acerca da incorporação do resíduo nos blocos, foi constatado que torna-se inviável a sua utilização como agente aglomerante na mistura, tendo em vista que não propicia a formação de silicato hidratado de cálcio na mistura, o que resulta em valores pouco significativos no que concerne aos resultados das propriedades físicomecânicas.

PALAVRAS-CHAVE: bloco sílico-calcário; resíduo calcário, propriedades físico-mecânicas.

\section{PHYSICAL AND MECHANICAL PROPERTIES OF BLOCKS SÍLICO LIMESTONES INCORPORATING CALCAREOUS RESIDUE}

\begin{abstract}
This research presents a study of experimental character gone back to the incorporation of calcareous residue in formulations of blocks silico-limestones to structural masonry, evaluating the technical viability of production of these through the determination of its, physical and mechanical properties, represented in this research by the lineal shrinkage of cure, water absorption, apparent porosity, bulk density and flexural strength in three points. One of the foundations of the accomplishment of this
\end{abstract}

research refers to the possibility of minimizing the current environmental impacts of the exploration of the calcareous rock. At the end of the study concerning the incorporation of the residue in the blocks, it was verified that becomes unviable its use as biding agent in the mixture, tends in view that non provides the formation of moisturized silicate of calcium in the mixture, what results in values a little significant in what it concerns to the results of the physical and mechanical properties.

KEY-WORDS: block sílic-limestone; calcareous residue, physical and mechanical properties. 


\section{PROPRIEDADES TECNOLÓGICAS DE BLOCOS SÍLICO CALCÁRIOS INCORPORANDO RESÍDUO CALCÁRIO}

\section{INTRODUÇÃO}

Os blocos sílico-calcários (BSC) são definidos pela ABNT através da norma NBR 149741: 2003 (Bloco sílico-calcário para alvenaria - Parte 1: Requisitos, dimensões e métodos de ensaio) como blocos prismáticos para alvenaria, fabricados com cal e agregados finos de quartzo, que depois da mistura íntima são moldados em peças, por pressão e compactação, sofrendo posteriormente endurecimento sob ação de calor e pressão de vapor.

A consolidação mecânica dos BSC's se deve a formação de fases a base de silicado de cálcio hidratadas, que formam uma matriz ligante envolvendo os grãos de sílica do agregado. A formação destas fases só é possível combinando elevadas temperaturas e altas pressões de vapor.

A concepção dos BSC's através da incorporação do tratamento hidrotermal (cura sob pressão de vapor) na manufatura destes representou o grande avanço tecnológico destes materiais, pois permitiu a confeç̧ão de blocos com características mecânicas compatíveis com a sua utilização em alvenarias estruturais, visto que, até então, estes limitavam-se a aplicação como elementos vedativos em edificações.

$\mathrm{Na}$ construção civil, os BSC podem ser utilizados em substituição aos blocos convencionais, pois normalmente apresentam algumas vantagens sobre eles, dentre as quais possuem relativa simplicidade no processo de manufatura, excelente uniformidade geométrica e aparência, resultando em elevada qualidade técnica. Podem ser usados em todas as formas e tamanhos de conformidade com o mercado e com os padrões específicos (ANDRADE, 2009).

Dentre as vantagens dos BSC's destacadas por REIS (2008, apud ANDRADE, 2009 , p.18) destacam-se a dispensa de chapisco e emboço no revestimento, além do que não é preciso regularizar a parede, é bastante nivelado, e pode ficar aparente ou receber uma fina camada de revestimento. Logo, a aplicação dos BSC's nas edificações representam grande economia de material de acabamento e mão-de-obra. Estudos estão sendo feitos na tentativa de reduzir o seu peso, que representa a desvantagem em relação aos blocos convencionais.

A pesquisa realizada tem caráter experimental e possui como objetivo geral estudar a viabilidade técnica da produção de blocos sílico-calcários com adição de resíduo calcário em suas formulações, atentando para as propriedades tecnológicas dos blocos de acordo com a substituição gradativa da cal por resíduo calcário, observando sempre se os resultados obtidos atendem aos requisitos exigidos pela ABNT - NBR 14974-1: 2003 - Bloco sílico-calcário para alvenaria Parte 1: Requisitos, dimensões e métodos de ensaio. As propriedades tecnológicas estudadas foram a retração linear, absorção de água, porosidade aparente, massa específica aparente e módulo de ruptura à flexão em três pontos. 
A problemática envolvendo o resíduo calcário consiste na percepção de que, as empresas de materiais de construção de Mossoró, mais especificamente as que trabalham no ramo de britagem da rocha calcária, produzem diariamente um grande volume deste sem que o mesmo possua destino adequado. Segundo cálculos de uma das empresas, temos que para cada $12 \mathrm{~m}^{3}$ de pedra calcária britada, tem-se $1,5 \mathrm{~m}^{3}$ de resíduo, que acaba por ser depositado no ambiente de forma incorreta, invadindo locais de vegetação e faunas sensíveis, além da poluição visual provocada pelo acúmulo destes resíduos em pilhas, caracterizando assim um grande impacto ambiental.

A utilização de resíduo calcário em formulações de blocos sílico-calcários representa, portanto, uma alternativa para minimizar os impactos ambientais decorrentes da exploração da britagem de rocha calcária, além de outros benefícios como melhor aproveitamento das matérias-primas, reduzindo custos de produção e maximizando lucros, tornando a atividade ecologicamente correta e economicamente sustentável.

\section{MATERIAIS E MÉTODOS}

\subsection{Caracterização das matérias-primas}

As matérias primas utilizadas foram areia fina, cal hidratada tipo $\mathrm{CH}$ III e resíduo calcário. A areia e o resíduo calcário foram sedidos por uma empresa de britagem de calcário e de produção de materiais de contrução situada na cidade de Mossoró. A cal foi disponibilizada pelo laboratório de construção civil do IFRN - Campus Mossoró.

A areia coletada passou por um processo de secagem em estufa elétrica com termostato regulado em $110^{\circ} \mathrm{C} \pm 5^{\circ} \mathrm{C}$ por um período de 24 horas. Terminada esta estapa foram colhidas amostras representativas para caracterização por análise granulométrica, que seguiu as recomendações da ABNT - NBR 7217 (Agregados - Determinação da Composição Granulométricas).

A empresa que disponibilizou o resíduo calcário o entregou moído e seco. O resíduo também já havia passado por um peneiramento prévio na peneira ABNT \#48 (abertura $0,30 \mathrm{~mm}$ ). Estas amostras de resíduo foram submetidas aos mesmos ensaios de composição granulométrica descritos para a areia.

Para a areia e resíduo, além dos ensaios de composição granulométrica também foram realizados ensaios para determinação de suas massas específicas. $O$ ensaio empregado foi o do frasco de Chapman, seguindo as prescrições da ABNT - NBR 9776 Agregados Determinação da massa específica por meio do frasco de Chapman.

A tabela 1 apresenta os resultados obtidos para a caracterização das matérias-primas através de seus índices físicos. 
Tabela 1: Índices Físicos das Matérias Primas.

\begin{tabular}{cccc}
\hline Material & $\begin{array}{c}\text { Módulo de } \\
\text { Finura (\%) }\end{array}$ & $\begin{array}{c}\text { Diâmetro Máximo } \\
(\mathbf{m m})\end{array}$ & Massa Específica $\left(\mathrm{g} / \mathrm{cm}^{\mathbf{3}}\right)$ \\
\hline Areia & 2,73 & 1,2 & 2,59 \\
\hline $\begin{array}{l}\text { Resíduo } \\
\text { Calcário }\end{array}$ & 1,76 & & 2,52 \\
\hline
\end{tabular}

Na tabela 1 pode ser constatada que ambas as matérias-primas, areia e resíduo calcário, apresentam granulometria fina, tendo em vista os valores obtidos para o diâmetro máximo das partículas. Esta informação é de suma importância, já que permite prever um melhor grau de empacotamento da mistura, resultando na formação de peças com superfícies lisas e arestas vivas.

\subsubsection{Curvas de Caracterização Granulométrica dos Materiais}

A seguir são apresentadas as curvas de composição granulométrica da areia e do resíduo calcário adotados nesta pesquisa, na figura 1.

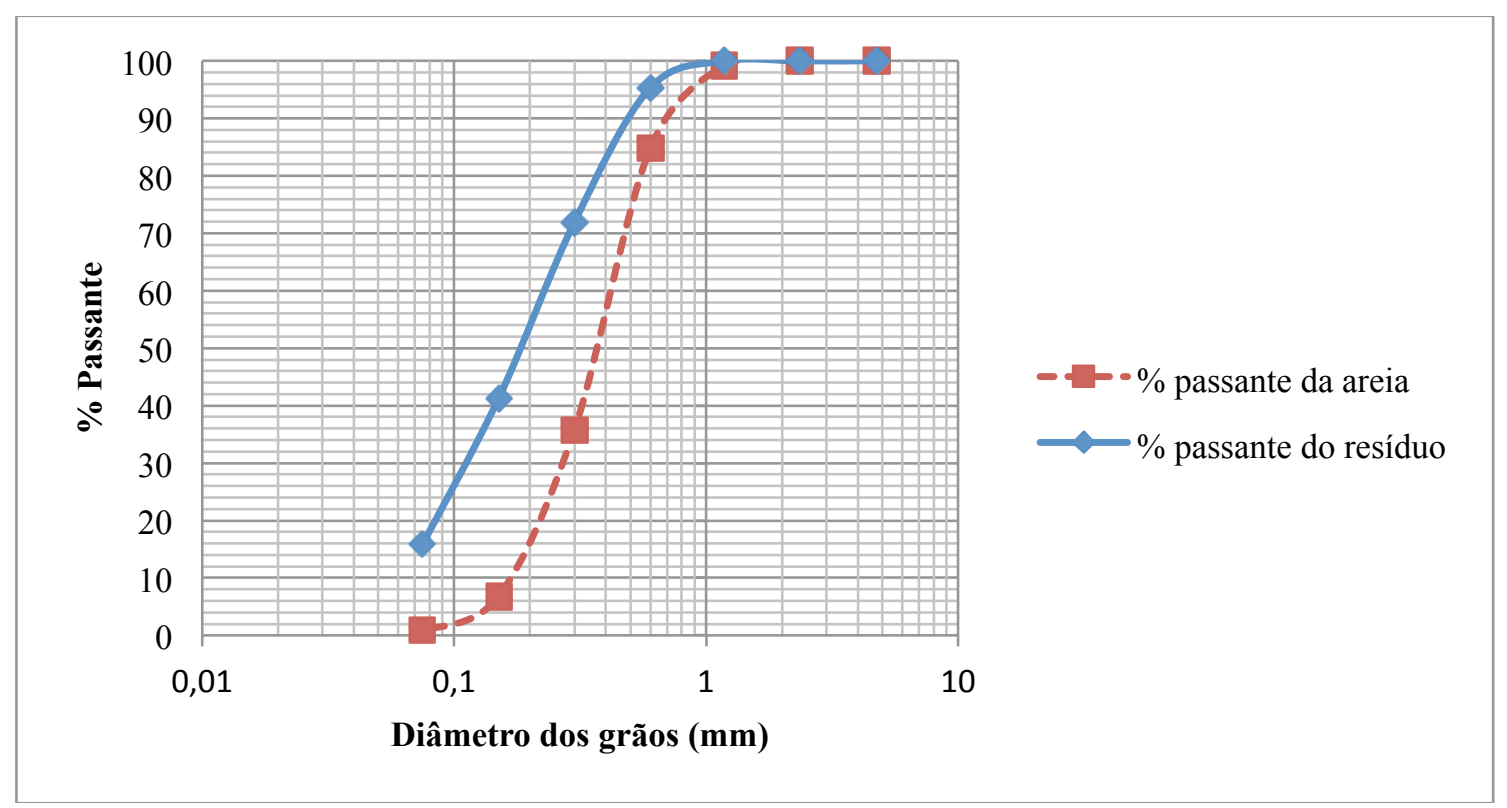

Figura 1: Composição Granulométrica da areia e resíduo calcário estudados. 
Pela figura 1 é constatado que o agregado utilizado na pesquisa apresenta uma granulometria fina, sendo identificados maiores percentuais de areia para a granulometria entre $0,1 \mathrm{~mm}$ e $1 \mathrm{~mm}$.

No que diz respeito a composição granulométrica do resíduo, também é constatada uma predominância de partículas de diâmetros entre 0,1 $\mathrm{mm}$ e $1 \mathrm{~mm}$, apresentando portanto uma granulometria fina. Observa-se, porém, que o resíduo calcário dispõe de uma granulometria menor que a da areia.

\subsection{Preparação da Massa Sílico-Calcária}

A areia e o resíduo calcário foram secos em estufa termelétrica. Ambos foram previamente passados em peneira ABNT \#65 (abertura $212 \mu \mathrm{m}$ ), tomado apenas o material passante para efeitos de estudo. Este material foi armazenado em sacos plásticos vedados, objetivando evitar variações na umidade. A cal hidratada dispensa este tipo de peneiramento, já que sua granulometria é bem definida na produção industrial.

No preparo da massa foram empregados traços em massa, sendo fixadas as porcentagens de cal, areia e resíduo calcário segundo a tabela 2 a seguir:

Tabela 2: Formulações das massas sílico-calcárias estudadas.

\begin{tabular}{cccc}
\hline & $\begin{array}{c}\text { Areia (\%) } \\
\left(\mathbf{S i O}_{\mathbf{2}}\right)\end{array}$ & $\begin{array}{c}\text { Cal Hidratada (\%) } \\
\left(\mathbf{C a}(\mathbf{O H})_{2}\right)\end{array}$ & $\begin{array}{c}\text { Resíduo calcário } \\
\left(\mathrm{CaCO}_{3}\right)\end{array}$ \\
\hline Formulação & 88 & 12 & 0 \\
\hline BSC-A & 88 & 9 & 3 \\
\hline BSC-C & 88 & 6 & 6 \\
\hline BSC-D & 88 & 3 & \\
\hline
\end{tabular}

Adicionou-se $10 \%$ de água em massa a cada formulação, umedecendo-as para posterior homogeneização manual. Em seguida, procedeu-se à granulação em peneira ABNT de malha 35 mesh (abertura $425 \mu \mathrm{m}$ ), a fim de proporcionar características próximas a de um material atomizado.

Após esta etapa as amostras foram armazenadas em sacos plásticos vedados a fim de evitar o ressecamento do material e proporcionar uma melhor uniformização da umidade.

\subsection{Preparação dos corpos-de-provas}

Foram confeccionados 3 corpos-de-prova para cada formulação. Os corpos-de-prova prismáticos foram conformados em laboratório por meio de molde de arestas $10 \mathrm{~cm}$ de 
comprimento $\times 5 \mathrm{~cm}$ de largura, sendo utilizada nesta etapa prensagem uniaxial de $30 \mathrm{MPa}$ (prensa hidráulica manual, Servitech $30 t$ - modelo CT-320).

\subsection{Secagem dos corpos-de-provas}

Esta etapa consiste na secagem dos corpos-de-prova ao ar livre, em condições normais de temperatura e pressão por um período de 24 horas. Neste caso a secagem ocorreu em ambiente de laboratório.

Imediatamente após a secagem dos corpos-de-prova, todos estes tiveram suas arestas medidas através de paquímetro digital com precisão de $0,01 \mathrm{~mm}$ para posterior determinação da retração linear de cura. A massa dos corpos-de-prova também foi computada para posterior determinação da absorção de água.

\subsection{Cura dos corpo-de-provas}

O processo de cura adotado consiste no tratamento hidrotermal dos corpos-de-prova em autoclave através da exposição destes à altas temperaturas e pressões controladas. Este método caracteriza-se principalmente pela rápida consolidação mecânica do compacto prensado.

O tratamento hidrotermal teve duração de 2 horas, das quais a primeira hora foi o tempo necessário para se atingir a pressão de $20 \mathrm{Kgf} / \mathrm{cm}^{2}$ e temperatura aproximada de $210^{\circ} \mathrm{C}$.

\subsection{Propriedades físico-mecânicas dos corpos-de-provas curados}

Os corpos-de-prova tiveram suas propriedades físico-mecânicas avaliadas em ensaios padronizados. Os. ensaios efetuados foram os de retração linear de cura (RL), absorção de água (AA), porosidade aparente (PA), massa específica aparente (MEA) e módulo de ruptura à flexão em três pontos.

Para todas as propriedades o resultado final foi obtido por uma média dos resultados obtidos dos três corpos-de-prova de cada formulação, proporcionando assim valores mais precisos para cada formulação e uma análise mais criteriosa.

\subsubsection{Retração Linear}

Esta propriedade refere-se a variação dimensional dos corpos-de-prova após o tratamento hidrotermal. Os valores são calculados pela diferença de medida nas arestas antes e após a cura. Para este ensaio fez-se necessário o uso de paquímetro digital de resolução 
0,01 mm. A metodologia utilizada neste ensaio foi similar a de ANDRADE (2009). Os valores de retração linear foram obtidos segundo a equação:

$R L(\%)=\frac{L s-L c}{L s} \times 100$

Onde:

- $\mathrm{Ls}=$ comprimento do corpo-de-prova seco a temperatura ambiente $(\mathrm{cm})$

- $\mathrm{LC}=$ comprimento do corpo-de-prova após cura $(\mathrm{cm})$

- $\mathrm{RL}=$ retração linear de cura (\%)

\subsubsection{Absorção de água}

Esta propriedade relata a quantidade de água que uma determinada massa de bloco sílico-calcário absorve em situações de muita umidade. A ABNT NBR 14974 - 1: 2003 prescreve que o valor da absorção de água deve estar entre $10 \%$ e $18 \%$. 0 ensaio realizado seguiu esta mesma norma para determinação da absorção de água. Os valores da massa foram obtidos em balança digital de alta precisão. Os resultados da absorção de água foram obtidos segundo a equação:

$A A(\%)=\frac{M u-M s}{M s} \times 100$

Onde:

- $\mathrm{Mu}=$ Massa do corpo-de-prova saturado (g)

- $\mathrm{Ms}=$ Massa do corpo-de-prova curado (g)

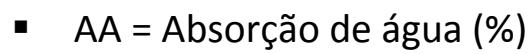

\subsubsection{Porosidade Aparente}

Esta propriedade representa a relação entre o volume de vazios (poros) dos corpos-deprova e o volume dos mesmos. Neste ensaio foi utilizado o método de Arquimedes, empregando-se a água como fluido de imersão. Foram tomadas as medidas de massa dos corpos-de-prova imersos em água através do método da balança hidrostática. Para o cálculo de propriedade também se faz necessário os valores das massas dos corpos-de-prova secos e saturados. A metodologia utilizada neste ensaio foi similar a de SANTOS (1985) e ANDRADE (2009). Os resultados da porosidade aparente foram obtidos segundo a equação:

$P A(\%)=\frac{M u-M c}{M u-M i} \times 100$

Onde:

- $\mathrm{Mu}=$ Massa do corpo-de-prova saturado (g) 
- $\mathrm{Mc}=$ Massa do corpo-de-prova curado (g)

- $\mathrm{Mi}=$ Massa do corpo-de-prova imerso em água (g)

\subsubsection{Massa Específica Aparente}

Esta propriedade representa a relação entre a massa do corpo-de-prova seco e o volume total do mesmo (volume aparente), incluindo o volume de vazios. Neste cálculo são consideradas as massas do corpo-de-prova curado, saturado e imerso em água. A metodologia utilizada neste ensaio foi similar a de SANTOS (1985) e ANDRADE (2009). Os resultados da massa específica aparente foram obtidos segundo a equação:

$\operatorname{MEA}\left(\mathrm{g} / \mathrm{cm}^{3}\right)=\frac{M c}{M u-M i} \times 100$

Onde:

- $\mathrm{Mc}=$ Massa do corpo-de-prova curado (g)

- $\mathrm{Mu}=$ Massa do corpo-prova saturado (g)

- $\mathrm{Mi}=$ Massa do corpo-de-prova imerso em água (g)

\subsubsection{Resistência Mecânica à flexão}

Esta propriedade foi avaliada através do ensaio de flexão em três pontos, sendo seus valores de suma importância para estudo preliminar da resistência mecânica dos blocos confeccionados com resíduo calcário. O ensaio foi realizado com uma velocidade de carregamento de $0,5 \mathrm{~mm} / \mathrm{min}$. e com distância fixa entre os apoios de $5,0 \mathrm{~cm}$, conforme decrito em ANDRADE (2009). Os valores da resistência mecânica à flexão foram obtidos segundo a equação:

$\operatorname{MRF}(M P a)=\frac{3 \times P \times d}{2 \times a \times b^{2}}$

Onde:

- $\mathrm{P}=$ Carga de ruptura $(\mathrm{N})$

- $\quad d$ = Distância entre os apoios do suporte $(\mathrm{mm})$

- $a=$ Largura do corpo-de-prova ( $\mathrm{mm})$

- $b=$ altura do corpo-de-prova $(\mathrm{mm})$

\subsection{Retração Linear de Cura}

Na tabela 3 são apresentados os resultados obtidos para retração linear de cura em corpos- de-prova incorporando resíduo calcário em diferentes proporções, submetendo-os ao mesmo tratamento hidrotermal de cura. 
Tabela 3: Retração linear de cura em porcentagem.

Formulação
Retração Linear

(\%)
Desvio Padrão
Coeficiente de Variação (\%)

\begin{tabular}{cccc}
\hline BSC - A & 0,076 & 0,051 & 66,909 \\
\hline BSC - B & 0,007 & 0,010 & 150,593 \\
\hline BSC - C & 0,106 & 0,061 & 57,302 \\
\hline BSC - D & $-0,060$ & 0,120 & $-201,006$ \\
\hline
\end{tabular}

Os resultados obtidos para retração linear de cura tiveram valores entre $0,007 \%$ e 0,106\%, apresentando valores mínimos a formulação B, que possui teor de cal hidratada de $9 \%$ e de resíduo calcário de $3 \%$. Os valores máximos de retração linear foram identificados na formulação $\mathbf{C}$, que apresenta teor de cal hidratada e de resíduo calcário iguais a $6 \%$ na mistura.

Segundo ANDRADE (2009), a variação dimensional por secagem dos blocos sílico calcários deve variar entre 0,01\% e 0,035\%. Nenhuma das formulações estudadas apresentou resultados que se enquadrassem nas recomendações da literatura estudada, sendo que a formulação B ( $9 \%$ de cal hidratada e $3 \%$ de resíduo calcário) não atingiu o limite inferior de retração linear estudado, o que pode ser interpretado positivamente como grande estabilidade dos corpos-de-prova durante o tratamento hidrotermal. No que diz respeito aos resultados do desvio padrão e coeficientes de variação, pode-se inferir que estas amostras de corpos-de-provas apresentaram grande variação de comportamento, visto que quando considerados os desvios, alguns corpos-de-prova se enquadraram nas recomendações da literatura, embora a média dos valores para uma mesma formulação não.

Para a formulação $\mathbf{D}$ foi constatado valores negativos de retração linear, o que pode ser interpretado como o aumento das arestas dos corpos-de-prova após o tratamento hidrotermal. Este aumento das arestas após a cura apresenta o inconveniente de aumentar a porosidade dos corpos-de-prova, resultando, por exemplo, em maior absorção de água e menor resistência mecânica à compressão.

\subsection{Absorção de água}

Na tabela 4 são apresentados os resultados obtidos para absorção de água em corposde-prova incorporando resíduo calcário em diferentes proporções, submetendo-os ao mesmo tratamento hidrotermal de cura. 
Tabela 4: Absorção de água em porcentagem.

\begin{tabular}{cccc} 
Formulação & $\begin{array}{c}\text { Absorção de Água } \\
\text { (\%) }\end{array}$ & Desvio Padrão & $\begin{array}{c}\text { Coeficiente de } \\
\text { Variação (\%) }\end{array}$ \\
\hline BSC-A & 15,35 & 1,327 & 8,647 \\
\hline BSC - B & 16,36 & 0,999 & 6,103 \\
\hline BSC - C & 16,25 & 1,212 & 7,457 \\
\hline BSC - D & 15,87 & 2,921 & 18,411 \\
\hline
\end{tabular}

Os resultados obtidos para o ensaio de absorção de água apresentaram valores entre $15,35 \%$ e $16,36 \%$, sendo os valores mínimos obtidos na formulação A (12\% de resíduo calcário), e os valores máximos identificados na formulação B ( $9 \%$ de cal hidratada e $3 \%$ de resíduo calcário).

A formulação $A$, tomada como parâmetro de estudo por não conter resíduo calcário em sua composição, apresentou a menor absorção de água dentre as formulações estudadas, indicando que o maior teor de cal permite o maior empacotamento da mistura. Vale salientar que a formulação A também apresentou os menores valores para retração linear, reforçando a idéia.

Todos os resultados obtidos no que concerne à propriedade de absorção de água se enquadram no patamar entre $11 \%$ e $18 \%$, respeitando assim o prescrito pela NBR 14974-1: 2003.

No que diz respeito aos resultados do desvio padrão e do coeficiente de variação das formulações, pode-se inferir que os corpos-prova da formulação B (9\% de cal hidratada e $3 \%$ de resíduo calcário) apresentaram os valores mais significativos, haja vista que seus resultados apresentaram os menores desvios. No entanto, de uma forma geral, os resultados do desvio padrão não interferem no enquadramento das formulações nas recomendações normativas.

\subsection{Porosidade aparente}

Na tabela 5 são apresentados os resultados obtidos para porosidade aparente em corposde-prova incorporando resíduo calcário em diferentes proporções, submetendo-os ao mesmo tratamento hidrotermal de cura.

Tabela 5: Porosidade aparente em porcentagem.

$\begin{array}{cccc}\text { Formulação } & \begin{array}{c}\text { Porosidade Aparente } \\ (\%)\end{array} & \text { Desvio Padrão } & \begin{array}{c}\text { Coeficiente de } \\ \text { Variação }\end{array}\end{array}$

$\begin{array}{llll}\text { BSC - A } & 26,97 & 1,047 & 3,882\end{array}$




\begin{tabular}{cccc} 
BSC - B & 28,72 & 1,291 & 4,494 \\
\hline BSC - C & 29,32 & 1,853 & 6,320 \\
\hline BSC - D & 28,43 & 4,378 & 20,797 \\
\hline
\end{tabular}

Os resultados obtidos para o ensaio de porosidade aparente apresentaram valores entre $26,97 \%$ e $29,32 \%$, sendo os valores mínimos obtidos na formulação $\mathbf{A}$ ( $12 \%$ de cal hidratada), e os maiores valores identificados na formulação C ( $6 \%$ de cal hidratada e $6 \%$ de resíduo calcário), Tabela 5 .

Como representado na tabela 5, o menor índice de porosidade aparente foi constatado na formulação $A$, servindo para reforçar a idéia proposta de que o maior teor de cal permite o maior empacotamento da mistura.

No que diz respeito aos resultados do desvio padrão e do coeficiente de variação das formulações, pode-se inferir que a formulação D (3\% de cal hidratada e $9 \%$ de resíduo calcário) apresenta comportamento muito variável, o que pode ser explicado pela menor estabilidade da mistura no que concerne ao empacotamento desta. As demais formulações apresentaram desvios pouco significativos já que seus coeficientes de variação são relativamente baixos.

\subsection{Massa específica aparente}

Na tabela 6 são apresentados os resultados obtidos para massa específica aparente em corpos-de-prova incorporando resíduo calcário em diferentes proporções, submetendo-os ao mesmo tratamento hidrotermal de cura.

Tabela 6: Massa específica aparente.

Os resultados obtidos no ensaio de massa específica aparente apresentaram valores entre $1,76 \mathrm{~g} / \mathrm{cm}^{3}$ e $1,81 \mathrm{~g} / \mathrm{cm}^{3}$. Os valores mínimos de massa específica aparente foram identificados nas formulações A ( $12 \%$ de cal hidratada) e B ( $9 \%$ de cal hidratada e $3 \%$ de resíduo calcário). Os valores máximos foram obtidos na formulação $\mathbf{C}$ ( $6 \%$ de cal hidratada e $6 \%$ de resíduo calcário), Tabela 6 . 
Segundo SANTOS (1985), a massa específica aparente deve variar entre 1,6 g/ $\mathrm{cm}^{3}$ e 2,1 $\mathrm{g} / \mathrm{cm}^{3}$. Logo, observando a Tabela 6 , verifica-se que todas as formulações apresentaram resultados compatíveis para os blocos sílico-calcários, ao menos no que concerne a esta propriedade.

No que diz respeito aos resultados do desvio padrão e do coeficiente de variação das formulações, pode-se inferir que estes são pouco significativos, já que não interferem no enquadramento das formulações nas recomendações normativas, além do que seus valores são relativamente uniformes.

Mais uma vez, como já previsto, a formulação A apresentou o melhor desempenho em termos de propriedades tecnológicas, consequência do maior teor de cal hidratada em sua composição.

\subsection{Módulo de ruptura à flexão em três pontos}

Na tabela 7 são apresentados os resultados obtidos para módulo de ruptura a flexão em três pontos em corpos-de-prova incorporando resíduo calcário em diferentes proporções, submetendo-os ao mesmo tratamento hidrotermal de cura.

Tabela 7: Módulo de ruptura à flexão em três pontos.

\begin{tabular}{cccc} 
Formulação & $\begin{array}{c}\text { Módulo de Ruptura à } \\
\text { flexão } \\
\text { (MPa) }\end{array}$ & Desvio Padrão & $\begin{array}{c}\text { Coeficiente de } \\
\text { Variação (\%) }\end{array}$ \\
\hline BSC-A & 2,75 & 0,014 & 0,514 \\
\hline BSC-B & 1,62 & 0,212 & 13,126 \\
\hline BSC - C & 1,32 & 0,444 & 33,651 \\
\hline BSC - D & 0,51 & 0,037 & 7,399 \\
\hline
\end{tabular}

Os resultados obtidos no ensaio de flexão apresentaram valores entre 0,51 MPa e 2,75 $\mathrm{MPa}$, sendo os valores mínimos identificados pela tabela na formulação $D$ ( $3 \%$ de cal hidratada e $9 \%$ de resíduo calcário), e apresentando maior módulo de flexão a formulação $A$ (12\% de cal hidratada).

Dentre as formulações que incorporaram resíduo na mistura, a formulação B ( $9 \%$ de cal hidratada e $3 \%$ de resíduo calcário) foi a que apresentou maior módulo de resistência à flexão, indicando que a resistência está diretamente ligada ao teor de cal hidratada incorporada na mistura. 
No que diz respeito aos resultados do desvio padrão e do coeficiente de variação das formulações, pode-se inferir que a formulação A ( $12 \%$ de cal hidratada) e B ( 9 \% de cal hidratada e $3 \%$ de resíduo calcário) apresentaram melhor comportamento, ou seja, resultados com menores desvios e, portanto, mais homogêneos, o que pode ser explicado pelo melhor empacotamento da mistura, resultado da maior formação de silicato hidratado de cálcio. Embora a formulação D (3 \% de cal hidratada e $9 \%$ de resíduo calcário) tenha apresentado desvio e coeficiente de variação menor que a formulação $B$, quando comparados com a média das resistências estes valores são pouco significativos. A formulação C ( $6 \%$ decal hidratada e $6 \%$ de resíduo calcário) apresentou comportamento muito heterogêneo, perceptível através de seu coeficiente de variação.

Os resultados apresentados indicam que a presença de resíduo de calcário reduz drasticamente as propriedades mecânicas. Este efeito indica que o resíduo atua como uma carga inerte, que não interage quimicamente com a sílica e com a cal. Deste modo, as partículas de calcário atuam como defeitos amplificadores de tensões mecânicas, o que explica a redução da resistência a tração sob flexão em três pontos.

\section{CONCLUSÕES}

Dos resultados obtidos nos ensaios e da análise das exigências para blocos sílico-calcários, conclui-se:

Dentre as formulações que incorporaram o resíduo calcário na mistura, a que apresentou resultados mais significativos quanto às propriedades tecnológicas foi a composta por $9 \%$ de cal hidratada e $3 \%$ de resíduo calcário.

A análise das formulações no que se refere à absorção de água permitiu concluir que todas as formulações estudadas satisfazem as exigência normativas da NBR 149741:2003, na qual o teor de absorção de água deve situar-se entre $11 \%$ e $18 \%$.

A incorporação de resíduo calcário em formulações de blocos sílico-calcários em substituição à cal hidratada acarreta redução de suas propriedades tecnológicas, comportando-se como uma carga inerte, e não como agente de reação na produção de silicatos de cálcio durante a autoclavagem. Uma alternativa para permitir a utilização do resíduo com esse intuito seria sua prévia ativação, mas que necessita de estudos que comprovem sua eficácia.

\section{REFERÊNCIAS BIBLIOGRÁFICAS}

1. ASSOCIAÇÃO BRASILEIRA DE NORMAS TÉCNICAS. NBR 14974-1. Bloco sílico-calcário para alvenaria - Parte 1: Requisitos, dimensões e métodos de ensaio. Rio de Janeiro, Ago/2003. 
2. ASSOCIAÇÃO BRASILEIRA DE NORMAS TÉCNICAS. NBR 7217. Determinação da Composição Granulométrica. Rio de Janeiro, Ago/1987.

3. ASSOCIAÇÃO BRASILEIRA DE NORMAS TÉCNICAS. NBR 9776. Agregados Determinação da massa específica de agregados miúdos por meio do frasco Chapman. Rio de Janeiro, Mar/1987.I

4. ANDRADE, J.C.S.; Estudo e caracterização de matérias-primas para o desenvolvimento de blocos sílico-calcários. 107f. Natal, UFRN, Curso de Pós Graduação em Engenharia Civil, 2009, Dissertação de Mestrado.

5. REIS, A.S. dos; Alvenaria Estrutural: uma visão do sistema construtivo. 2008. 82f. Monografia (Graduação em Engenharia Civil) - Pontifícia Universidade Católica do Rio Grande do Sul, Faculdade de Engenharia. Porto Alegre, 2008.

6. SANTOS, J.C.P.; Viabilidade Técnica da Produção de Blocos Sílico-Calcários na Região de Santa Maria, no Rio Grande do Sul. 200f. Dissertação (Mestrado) - Universidade Federal do Rio Grande do Sul: Porto Alegre, 1985. 